\title{
FUNGICIDA METALAXIL NA MICROBIOTA E NA ATIVIDADE ENZIMÁTICA DO SOLO
}

\author{
ALEX MORETINI * \\ ANDREA MARIA SPESSOTO ** \\ ITAMAR SOARES DE MELO ***
}

\begin{abstract}
Foram estudados os efeitos do metalaxil sobre a microbiota de solos coletados nos municípios paulistas de Aguai, Estiva Gerbi e Jaguariúna (Brasil), suplementados com doses de 3 e $30 \mu \mathrm{g}$ i.a. $\mathrm{g}^{-1}$ de metalaxil pelo período de 32 dias. Populações de bactérias, actinomicetos e fungos foram monitoradas mediante contagem em placas com meios de cultura seletivos e pela atividade enzimática da fosfatase ácida (Pase) e desidrogenase (Dhase). A Pase foi avaliada pelo método da $p$-nitrofenilfosfatase e a Dhase pela quantificação do vermelho formazan produzido. Houve predominância de populações bacterianas em todos os solos, sendo os maiores valores de UFC $\mathrm{g}^{-1}$ observados nos solos suplementados com a dose de $30 \mu \mathrm{g}$ i.a. $\mathrm{g}^{-1}$ de metalaxil. Populações de fungos apresentaram acentuado decréscimo após a incorporação do composto. A atividade Dhase foi inibida pela presença de metalaxil nos solos arenoso e controle. No solo argiloso houve acréscimo dessa atividade, mais significativo no período de 7 a 21 dias, nas duas doses de suplementação avaliadas. A atividade da Pase foi inibida em todos os três solos.
\end{abstract}

PALAVRAS-CHAVE: METALAXIL; DESIDROGENASE; FOSFATASE ÁCIDA; SOLOS.

* $\quad$ Engenheiro Agrônomo, Aluno de Doutorado em Biotecnologia, Universidade de São Paulo, SP.

** Bióloga, Doutora em Genética, Departamento de Genética, Universidade Federal de São Carlos, SP.

*** Pesquisador III, Embrapa Meio Ambiente, Jaguariúna, SP (e-mail: itamar@cnpma.embrapa.br). 


\section{INTRODUÇÃO}

Metalaxil, fungicida que apresenta efeito sistêmico e residual, encontra-se registrado em mais de 80 países. É empregado em cerca de 60 culturas de importância agrícola (como tomate, uva e citros), sendo amplamente utilizado no controle de patógenos de plantas da ordem Peronosporales (ARX, 1987).

O comportamento do metalaxil assume grande importância para estudos de impacto ambiental, principalmente, em áreas com aplicação contínua. Segundo MUSUMECI e RUEGG (1986), OSTIZ e MUSUMECI (1989), PAPINI e ANDRÉA (2000) e SPESSOTO et al. (2000), esse fungicida tem sido pouco estudado em solos brasileiros que apresentam características bióticas e abióticas completamente distintas dos solos de regiões temperadas.

A utilização de pesticidas em lavouras para controle de pragas e de doenças, muitas vezes, causa acúmulo desses compostos no ambiente. Um dos efeitos conhecidos de tal acúmulo envolve a capacidade dos pesticidas afetarem populações microbianas naturais, podendo favorece determinados grupos em detrimento de outros. Quando aplicados nas doses recomendadas, geralmente, os pesticidas apresentam baixa toxicidade para as comunidades microbianas nativas dos solos (HILL, 1978; SMITH, 1988). No entanto, altas concentrações podem inibir ou mesmo estimular determinadas populações ou atividades enzimáticas (JOHNSTON e CAMPER, 1991).

Os fungicidas, de modo geral, afetam os microrganismos por atuação direta nas membranas e organelas celulares, no núcleo e na atividade enzimática. Afetam também a fertilidade do solo já que essa não depende apenas de sua composição física e do teor de nutrientes, mas também da intensidade dos processos biológicos que nele ocorrem. O desequilíbrio desses processos pode se refletir diretamente nas interações entre plantas e microrganismos (TU e BOLLEN, 1968; DROZDOWISCZ, 1971; SANTOS, 1992).

Inúmeros trabalhos têm usado a atividade das desidrogenases em estudos toxicológicos e ecológicos. A redução de sais tetrazolium a formazan por células bacterianas é atribuída ao poder de deslocamento do elétron no sistema de transporte, podendo ser utilizado como indicador da atividade metabólica. VOSJAN (1982) demonstrou as aplicações desse método para estudos envolvendo amostras ambientais.

É de grande importância conhecer os efeitos de pesticidas sobre os microrganismos não-alvo e obter informações sobre seu impacto na microbiota de solos de regiões tropicais.

O presente trabalho teve como objetivos avaliar as variações no número de unidades formadoras de Colônias (UFC) de bactérias, actinomicetos e fungos e a atividade das enzimas desidrogenase e fosfatase ácida em três solos brasileiros suplementados com metalaxil.

\section{MATERIAL E MÉTODOS}

\subsection{SOLOS}

Foram estudados solos provenientes dos municípios de Aguaí-SP (Lat. 22 03' 45" S; Long. $46^{\circ}$

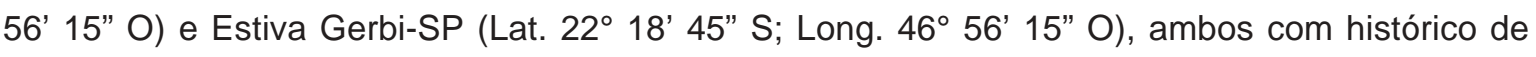
aplicação de metalaxil. As amostras foram coletadas em pomares de citros, na profundidade de 0-15 $\mathrm{cm}$, em área de 1 hectare, na região de projeção das copas das plantas. Amostras de solo de mata sem histórico de aplicação do fungicida foram coletadas na região de Jaguariúna-SP (Lat. 22 $41^{\prime}$ ' 15" S; Long. 46 56' 15" O). As coletas foram efetuadas a $15 \mathrm{~m}$ da margem da mata, em cinco pontos dentro do transecto. Todas as amostras foram tamisadas em peneiras de $2 \mathrm{~mm}$ e estocadas a $4^{\circ} \mathrm{C}$ até o início das análises, sendo determinadas a umidade e a capacidade de campo de todos os solos (EMBRAPA, 1997).

A textura e o histórico de utilização do fungicida, bem como os resultados das análises físicas e químicas dos solos estudados estão apresentadas nas Tabelas 1 e 2. 
TABELA 1 - TAXONOMIA, COMPOSIÇÃO, GRANULOMETRIA, CULTURA E HISTÓRICO DE APLICAÇÃO DOS SOLOS ESTUDADOS

\begin{tabular}{cccccccc}
\hline Solo & Taxonomia & Areia & Silte & Argila & Granulometria & Cultura & $\begin{array}{c}\text { Itima data } \\
\text { de } \\
\text { aplica a o }\end{array}$ \\
\hline Agua & $\begin{array}{c}\text { Latossolo Vermelho } \\
\text { Eutr fico T pico }\end{array}$ & $58 \%$ & $6 \%$ & $36 \%$ & Argilosa & Citros & Jan/99 \\
\hline Estiva Gerbi & $\begin{array}{c}\text { Latossolo Vermelho- } \\
\text { amarelo Eutr ficox }\end{array}$ & $82 \%$ & $4 \%$ & $14 \%$ & Arenosa & Citros & Jan/98 \\
\hline Jaguariona & Latossolo Vermelho & $52 \%$ & $6 \%$ & $42 \%$ & Argilosa & Floresta & $*$ \\
\hline
\end{tabular}

* Sem histórico de aplicação do fungicida.

TABELA 2 - CARACTERÍSTICAS QUÍMICAS DOS SOLOS ESTUDADOS *

\begin{tabular}{|c|c|c|c|c|c|c|c|c|c|c|}
\hline Solo & $\begin{array}{c}\mathrm{pH} \\
\mathrm{CaCl}_{2}\end{array}$ & $\begin{array}{l}\text { Matđria } \\
\text { org nica } \\
\mathrm{g} \mathrm{dm}^{-3}\end{array}$ & $\begin{array}{c}P \\
\mathrm{mg} \mathrm{dm}^{-3}\end{array}$ & $\mathrm{~K}$ & $\mathrm{Ca}$ & Mg & $\begin{array}{l}\mathrm{H}+\mathrm{Al} \\
\mathrm{mol} \mathrm{d}\end{array}$ & SB & $T$ & $\mathbf{v}$ \\
\hline Agua & 5,3 & 22 & 75 & 4,6 & 54 & 35 & 31 & 93,6 & 124,6 & 75 \\
\hline $\begin{array}{l}\text { Estiva } \\
\text { Gerbi }\end{array}$ & 5 & 17 & 37 & 1,7 & 35 & 11 & 20 & 47,7 & 67,7 & 70 \\
\hline Jaguariœ๓a & 3,6 & 30 & 6 & 1,6 & 1 & 2 & 121 & 4,6 & 125,6 & 4 \\
\hline
\end{tabular}

$\mathrm{H}+\mathrm{Al}=$ = Acidez Potencial, SB = Soma de Bases Trocáveis, $\mathrm{T}$ = Capacidade de Troca de Cátions, V = Saturação por Bases. * Análises realizadas pelo Departamento de Ciência do Solo da Escola Superior de Agricultura Luiz de Queiroz/USP, Piracicaba, São Paulo.

\subsection{FUNGICIDA}

Foi utilizado 35\% de ingrediente ativo de metalaxil [metil D,L,N-(2,6-dimetilfenil)-N-(2-metoxiacetil) alaninato] na suplementação dos solos.

\subsection{SUPLEMENTAÇÃO DOS SOLOS}

Sub-amostras (150 g peso seco) de cada solo foram colocadas em frascos erlenmeyer $(250 \mathrm{~mL})$, que receberam uma única suplementação do fungicida nas doses de 3 e $30 \mu \mathrm{g} \mathrm{i.a.} \mathrm{g}^{-1}$. Os controles foram efetuados com solos sem a suplementação do fungicida. Os solos foram mantidos úmidos ( $70 \%$ da capacidade de campo) e incubados a $25^{\circ} \mathrm{C}$.

\subsection{AVALIAÇÃO DAS POPULAÇÕES MICROBIANAS}

Efetuou-se o monitoramento de populações microbianas (bactérias, actinomicetos e fungos) mediante contagem periódica em meios de cultura. Sub-amostras de $1 \mathrm{~g}$ (peso seco) de cada solo, retiradas dos frascos erlenmeyer, foram ressuspensas em tubos de ensaio contendo $9 \mathrm{~mL}$ de solução salina $(0,08 \%)$ esterilizada. Após 2 min de agitação em vortex transferiram-se alíquotas para tubos em que foram realizadas diluições apropriadas. De cada diluição (triplicata) foram transferidos $100 \mu \mathrm{L}$ para placas contendo os meios indicados na Tabela 3. 
TABELA 3 - MEIOS DE CULTURA UTILIZADOS

\begin{tabular}{|c|c|c|}
\hline M ICRORG A NISMOS & MEIOS & Q U A N TID A DE \\
\hline B actØrias & $\begin{array}{c}\text { Nutriente gar } \\
\text { Peptona } \\
\text { Extrato de carne } \\
\text { gar }\end{array}$ & $\begin{array}{c}1000 \mathrm{~m} \mathrm{~L} \mathrm{H} \mathrm{H}_{2} \mathrm{O} \\
0,50 \% \\
0,30 \% \\
1,5 \%\end{array}$ \\
\hline Fungos & $\begin{array}{c}\text { Meio de Martin* } \\
\mathrm{KH}_{2} \mathrm{PO}_{4} \\
\mathrm{MgSO}_{4} 7 . \mathrm{H}_{2} \mathrm{O} \\
\mathrm{Peptona} \\
\text { Dextrose } \\
\text { Rosa Bengala } \\
\text { Estreptomicina (Sigma) } \\
\text { gar }\end{array}$ & $\begin{array}{c}1000 \mathrm{~m} \mathrm{~L} \mathrm{H}{ }_{2} \mathrm{O} \\
1 \% \\
0,5 \% \\
5 \% \\
10 \% \\
0,033 \% \\
772 \mathrm{~g}-0,03 \% \\
1,5 \%\end{array}$ \\
\hline Actinom icetos & 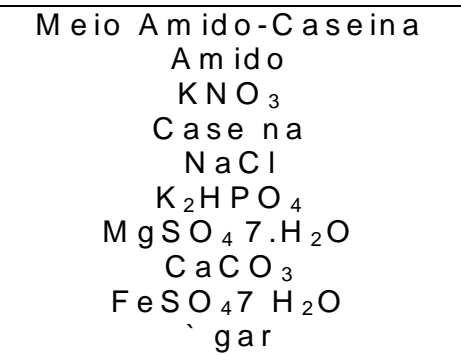 & $\begin{array}{c}1000 \mathrm{~m} \mathrm{~L} \mathrm{H}_{2} \mathrm{O} \\
10 \% \\
2 \% \\
0,3 \% \\
2 \% \\
2 \% \\
0,05 \% \\
0,02 \% \\
0,01 \% \\
1,5 \%\end{array}$ \\
\hline
\end{tabular}

${ }^{*}$ MARTIN (1950).

As unidades formadoras de colônias (UFC) foram estimadas nos intervalos de 0, 2, 4, 7, 14, 21 , 28 e 32 dias.

\subsection{ANÁLISES DA ATIVIDADE ENZIMÁTICA DAS ENZIMAS DESIDROGENASE E FOSFATASE ÁCIDA}

A atividade da desidrogenase foi determinada segundo metodologia de ALEF (1995). Subamostras ( $5 \mathrm{~g}$ peso seco) retiradas dos solos receberam $5 \mathrm{~mL}$ de cloreto de 2, 3, 5-trifeniltetrazolium (TTC) e $1 \%$ de carbonato de cálcio, sendo incubadas no escuro a $37^{\circ} \mathrm{C}$ por 24 horas. Após esse período foi determinado o trifenilformazam (TTF) formado pela redução do TTC a TTF, mediante extração com metanol. Paralelamente, construiu-se a curva-padrão por meio de diluições de TTF em metanol nas concentrações de 3 a $27^{1} \mu \mathrm{g} \mathrm{mL}{ }^{-1}$. Efetuou-se a leitura em espectrofotômetro marca Shimadzu, modelo UV-1601 PC, a $485 \mathrm{~nm}$. Os valores de TTF foram convertidos em $\mu \mathrm{L}$ de H (1 mg de TTF equivale a $150,35 \mu \mathrm{L}$ de $\mathrm{H})$.

A atividade fosfatase ácida também foi determinada segundo metodologia descrita por ALEF (1995). Sub-amostras dos solos (1 g peso seco) receberam $4 \mathrm{~mL}$ de tampão maleato 0,1M pH 6,5 e $1 \mathrm{~mL}$ de $\mathrm{p}$-nitrofenilfosfato $0,025 \mathrm{M}$, sendo incubadas a $37^{\circ} \mathrm{C}$ por 1 hora. Após esse período, adicionouse $1 \mathrm{~mL}$ de $\mathrm{CaCl}_{2}$ 0,5M e $4 \mathrm{~mL}$ de $\mathrm{NaOH}$ 0,5M. Filtrou-se a solução em papel Whatman oㅜ 1. Os controles foram preparados da mesma maneira, embora a enzima tenha sido adicionada de hidróxido de sódio antes da incorporação de cloreto de cálcio. Construiu-se a curva-padrão a partir de solução estoque a $1 \%$ de $p$-nitrofenol, sendo retiradas alíquotas de 0,$2 ; 0,4 ; 0,6 ; 0,7 ; 0,8 ; 1 ; 2 ; 4 ; 6$ e $8 \mathrm{~mL}$ e seus volumes completados para $10 \mathrm{~mL}$ com água destilada. $\mathrm{O} p$-nitrofenol formado foi determinado em espectrofotômetro a $400 \mathrm{~nm}$ e os resultados expressos como $\mu \mathrm{g}$ de $\mathrm{p}$-nitrofenol liberado em 1 hora $\mathrm{g}^{-1}$ solo. 


\subsection{ANÁLISE ESTATÍSTICA}

Testes de Variância Múltipla de Duncan e de Tukey foram efetuados com o auxílio do aplicativo STATISTICA (2002) para os dados obtidos nos experimentos de fosfatase ácida e desidrogenase (nível de significância nos testes de $P=\leq 0,05)$.

\section{RESULTADOS E DISCUSSÃO}

A incorporação do fungicida ao solo promoveu acentuado aumento no número de bactérias (Figuras 1, 2 e 3) em todos os três solos avaliados. O solo de Aguaí destacou-se quanto a esse fenômeno a partir do segundo dia após a aplicação do composto. Observou-se aumento no número de bactérias em ambas as dosagens empregadas, sendo mais evidente aos 32 dias de incubação no tratamento correspondente a maior dosagem de metalaxil. Populações bacterianas estariam sendo favorecidas pela suplementação (ao solo) de fonte de carbono exógena. Assim, maior correlação do fungicida aplicado e mais alta a tolerância da microbiota ao composto incrementa a biomassa, aumentando a aceleração do metabolismo.

\section{FIGURA 1 - Log $10 \times 10^{-4}$ DE UFC g-1 SOLO DE BACTÉRIAS, ACTINOMICETOS E FUNGOS OBTIDAS NO INTERVALO DE 32 DIAS DE INCUBAÇÃO DO SOLO DE AGUAÍ COM 3 E $30 \mu$ g i.a. g $^{-1}$ DE METALAXIL*}

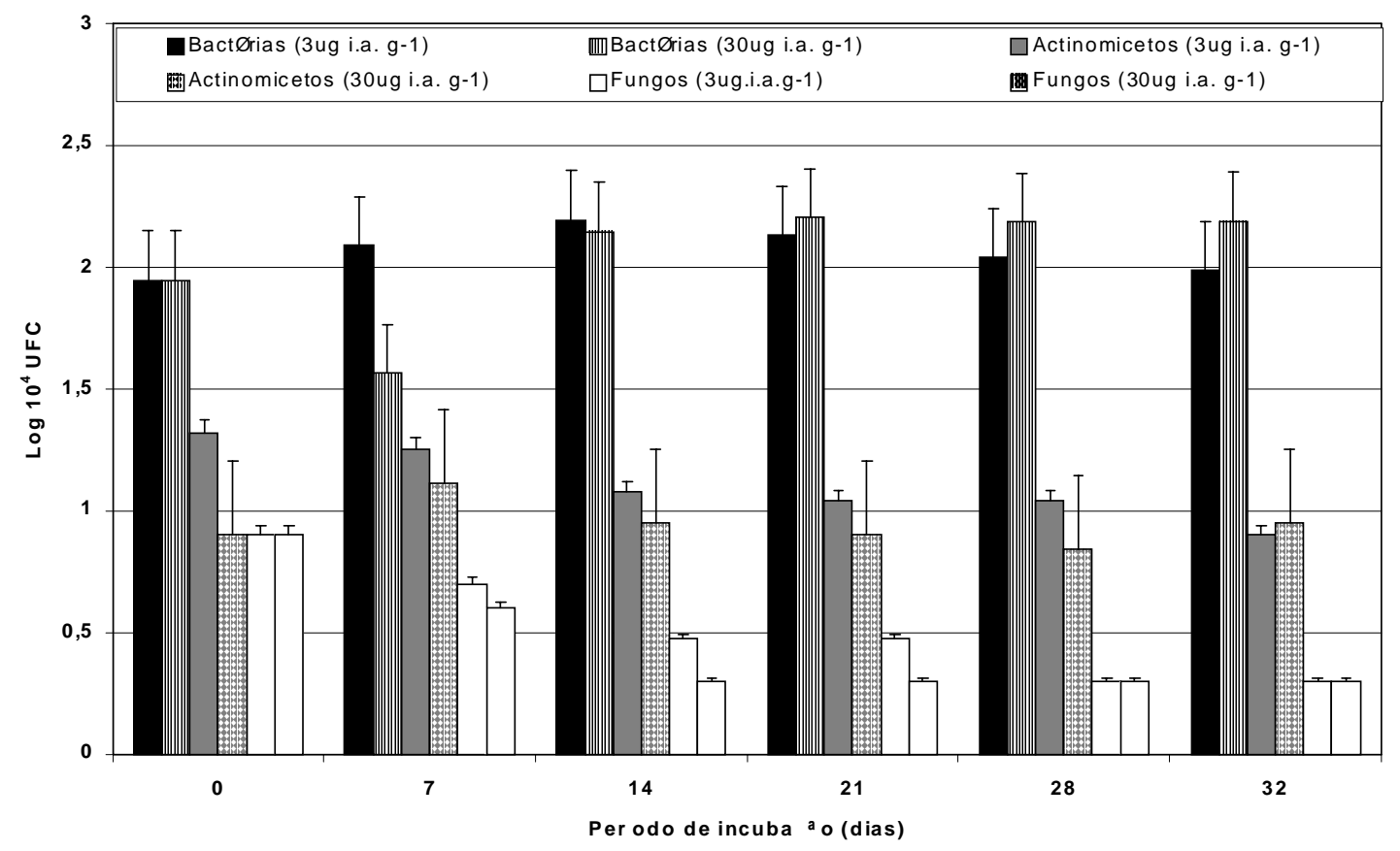

* As barras indicam o desvio-padrão.

No caso dos solos de Estiva Gerbi-SP, as bactérias apresentaram aumento acentuado no seu número nos primeiros 4 dias de incubação. Houve leve decréscimo nesse número ao final da primeira semana, seguido de estabilização. Nos solos de Jaguariúna-SP (sem histórico de utilização do fungicida em campo), o número de UFC $\mathrm{g}^{-1}$ de bactérias acompanhou os dados obtidos pelos controles até o $14^{\circ}$ dia de incubação. Verificou-se então, acentuado aumento nesse número para a dose de $3 \mu \mathrm{g} \mathrm{i.a} \mathrm{g}^{-1} \mathrm{de}^{\circ}$ metalaxil, que se manteve alto até os 21 dias. Posteriormente, esses valores decresceram até o final dos 32 dias de incubação. 
FIGURA 2 - Log $10 \times 10^{-4}$ de UFC. - $^{-1}$ SOLO DE BACTÉRIAS, ACTINOMICETOS E FUNGOS OBTIDAS NO INTERVALO DE 70 DIAS DE INCUBAÇÃO DO SOLO DE ESTIVA GERBI COM 3 E $30 \mu$ g i.a. g $^{-1}$ DE METALAXIL*

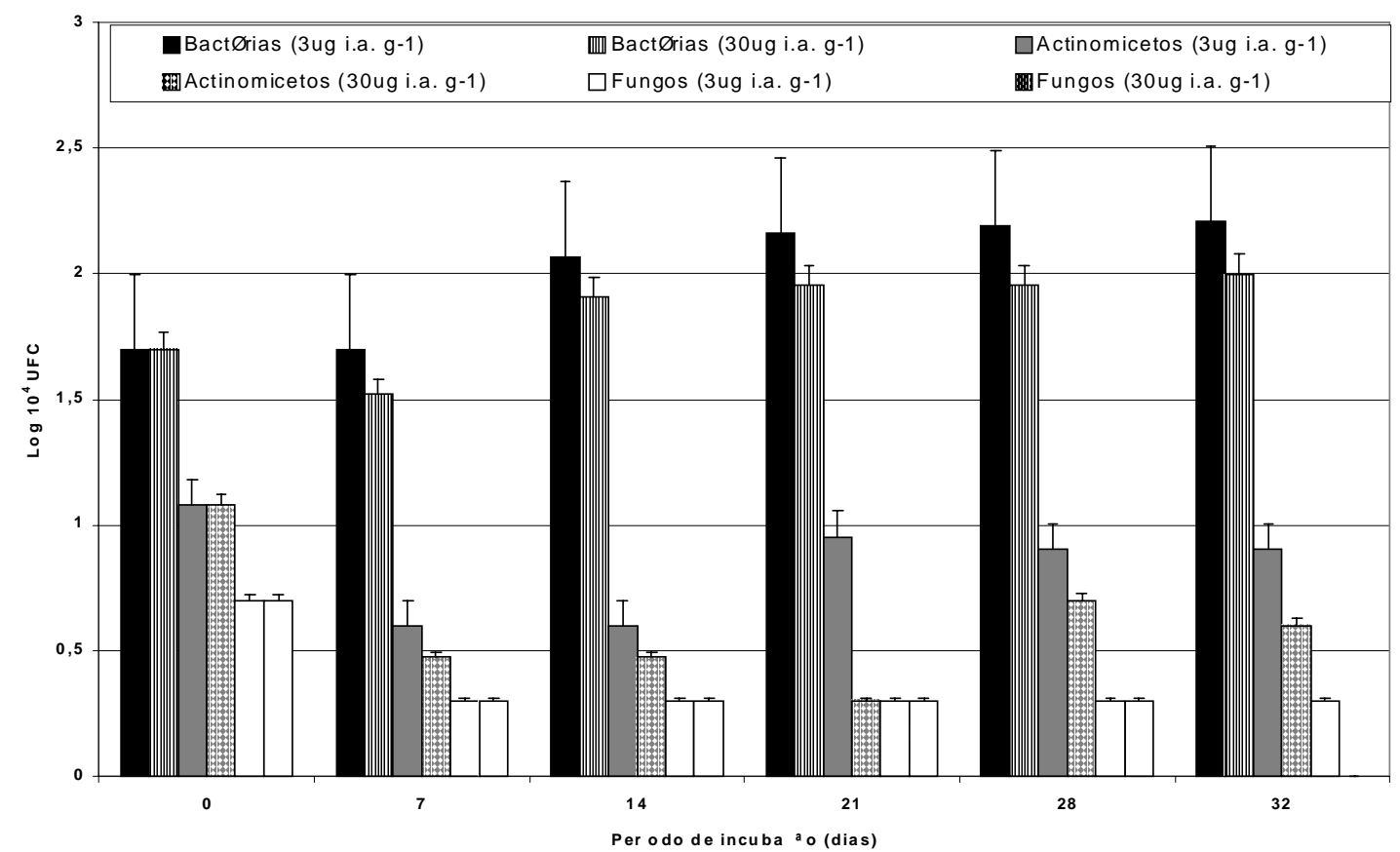

* As barras indicam o desvio-padrão.

FIGURA 3 - Log $10 \times 10^{-4}$ de UFC.g ${ }^{-1}$ SOLO DE BACTÉRIAS, ACTINOMICETOS E FUNGOS OBTIDAS NO INTERVALO DE 70 DIAS DE INCUBAÇÃO DO SOLO DE JAGUARIÚNA COM 3 E $30 \mu$ i.a. g $^{-1}$ DE METALAXIL*

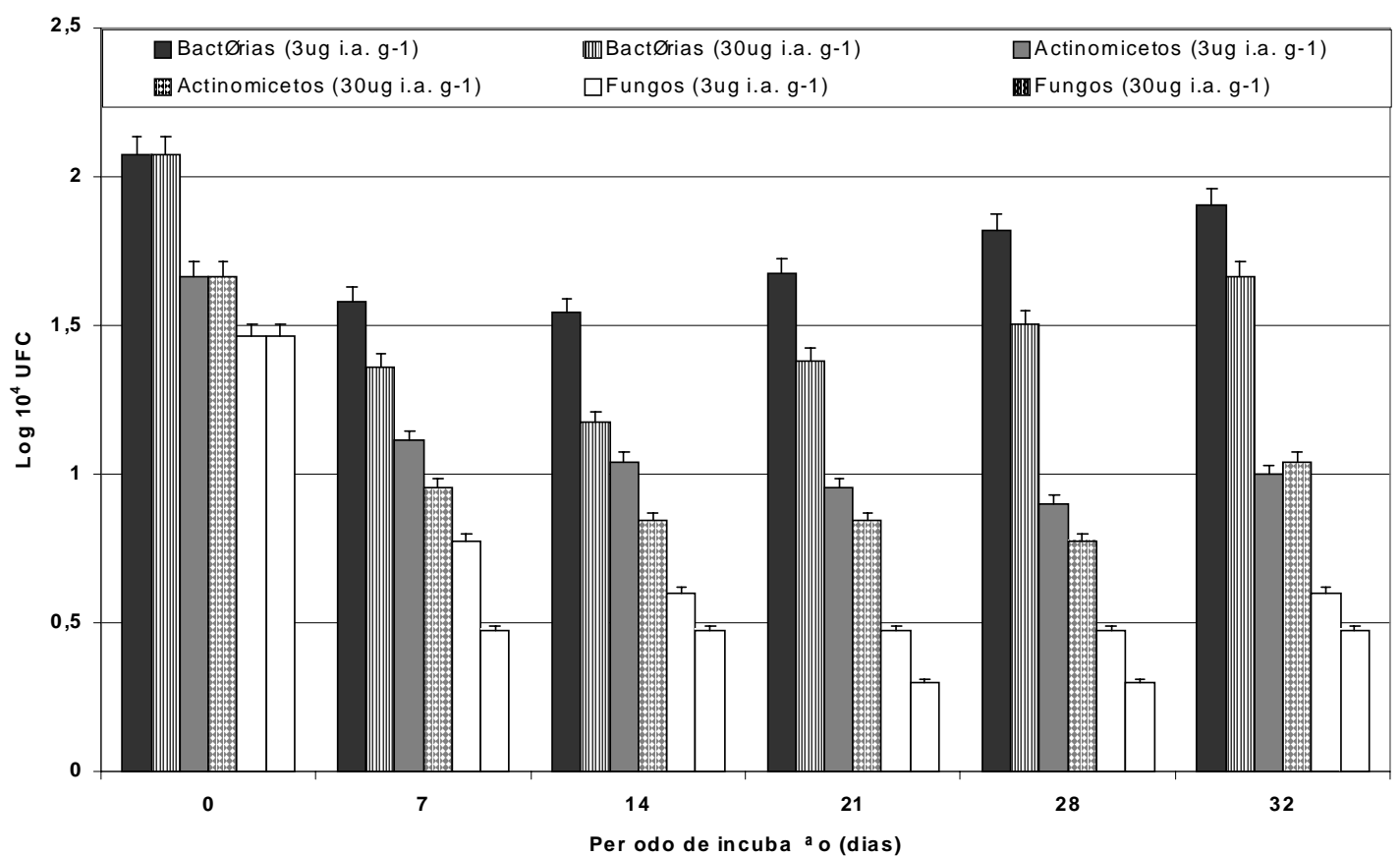

* As barras indicam o desvio-padrão. 
Estudos já demonstraram que a presença de fungicidas no solo pode estimular o crescimento de populações bacterianas (ANDERSON, 1978; BAILEY e COFFEY, 1986) para as quais é conferida a capacidade de utilizar esses compostos como fonte de carbono e energia. Tendo cumprido seu papel como fungicida, o metalaxil pode ter influenciado a diminuição no número de fungos e com isso minimizado a competição por nutrientes. Populações bacterianas presentes estariam sendo favorecidas, tanto pela falta dessa competição como também pelo aumento da biomassa bacteriana ocasionada por nutrientes orgânicos derivados de células mortas de outros microrganismos atingidos pelo fungicida. Além disso, deve-se considerar o histórico de pré-exposição dos solos de Aguaí e Estiva Gerbi ao fungicida em culturas de citros. Vários trabalhos vêm demonstrando que repetidas aplicações de pesticidas acabam por "capacitar" alguns segmentos da microbiota natural (pela ação da seleção e adaptação) a metabolizar o composto presente. Esse fenômeno, conhecido como biodegradação acelerada (RACKE, 1990), tem sido descrito como uma das causas da ineficiência do controle fitossanitário em condições de campo e como um dos fatores de rápida degradação de pesticidas. DROBY e COFFEY (1991) relataram que o metalaxil não apresenta efeitos negativos sobre bactérias, tendo atribuído à essas a responsabilidade pelo desaparecimento da molécula no solo.

Nos solos de Jaguariúna, não-expostos ao fungicida, os resultados demonstraram que os efeitos adversos do uso do metalaxil foram maiores para as bactérias. Entretanto, outros fatores como pH ácido e teor de matéria orgânica no solo devem ser considerados e podem ter contribuído para o baixo número de UFC de bactérias encontradas.

Ficou comprovado que a comunidade fúngica foi a mais afetada pela presença do metalaxil. Tais resultados estão em desacordo com os de BAILEY e COFFEY (1985), que não verificaram alterações nos níveis e composição das populações microbianas (tanto de fungos, como de bactérias ou de actinomicetos) expostos ao metalaxil. Já DROBY e COFFEY (1991) detectaram mudanças nas populações de microrganismos em solos com e sem histórico de aplicação do metalaxil. No caso desta avaliação, a ação fungicida do metalaxil mostrou-se maior do que a descrita na literatura e atingiu de forma negativa outras classes de fungos além daquelas para as quais foi inicialmente sintetizado. Fungos pertencentes à diferentes taxas foram observados nas placas controle, sem o fungicida, podendo-se avaliar a ação desse produto no solo. Essa informação é preocupante sob o ponto de vista ecológico, uma vez que confere ao metalaxil largo espectro de ação sobre a comunidade fúngica, podendo interferir em diversos outros nichos importantes para a manutenção da biodiversidade nesse ambiente. Deve-se ressaltar que ações antagonistas presentes nesses solos podem estar sendo comprometidas pelo desequilíbrio instalado na comunidade após a aplicação do metalaxil. Tais ações são importantes para a manutenção do controle natural de diversas outras doenças de interesse agrícola.

Os actinomicetos também apresentaram valores variáveis de acordo com o solo e tratamento. Solos coletados em Estiva Gerbi, suplementados com $30 \mu \mathrm{g} \mathrm{i.a.} \mathrm{g}^{-1}$ de metalaxil, revelaram os maiores valores de UFC nas placas avaliadas. Esse aumento foi observado nos solos de Aguai nas duas doses testadas, permanecendo durante todo o experimento. Os solos de Jaguariúna, com o menor número inicial de actinomicetos, apresentam valores baixos mesmo após a aplicação do fungicida. Aos 21 dias de incubação observou-se aumento dessas populações em ambas as doses. Entretanto, como o fenômeno também foi observado nos controles não foi possível relacioná-lo com a presença da molécula.

Os actinomicetos normalmente desenvolvem-se lentamente, variando seu tempo de incubação de acordo com os gêneros. A maioria das espécies de Streptomyces e formas relacionadas não proliferam ou apresentam baixa atividade em $\mathrm{pH}$ ácido. Esse fato pode explicar, no caso do solo de Jaguariúna com pH 3,6, o baixo número encontrado desse grupo de microrganismos. No entanto, não ficou demonstrado se o metalaxil exerce efeito negativo ou positivo acentuado para os actinomicetos. Após 21 dias, a molécula pode ter se tornado disponível para esse segmento de modo a alterar o pH do solo e servir como fonte de carbono para seu metabolismo. Além disso, produtos do metabolismo de outros segmentos da microflora podem ter servido de fonte de carbono e energia para os actinomicetos (FAROOQI et al., 1999). Da mesma forma, os actinomicetos são afetados pela presença de carbono 
disponível e seu número é bem maior em solos ricos em matéria orgânica. O pH e a matéria orgânica são fatores que podem estar favorecendo esses microrganismos nos solos de Aguaí, o que explicaria o aumento no número de actinomicetos observado aos 4 e 14 dias quando o fungicida se encontrava na maior dose. Entretanto, aos 21 dias houve redução das populações, restabelecendo-se de maneira mais lenta nas duas últimas semanas de avaliação. Aparentemente, os actinomicetos foram estimulados pela presença do fungicida. Suas populações que inicialmente se mostraram extremamente reduzidas nesse solo, após a suplementação tiveram seu número aumentado de maneira satisfatória no período subseqüente.

HILL (1978) afirmou que os pesticidas aplicados nas taxas recomendadas, geralmente não exercem efeito, ou apenas efeito transitório sobre os microrganismos do solo. Em concentrações excessivas, os compostos podem agir de maneira inibitória e afetar a população de uma ou de diferentes espécies, ou ainda, uma atividade bioquímica ou processo. Desta forma, populações microbianas nos solos que recebem doses excessivas de um pesticida podem ser profundamente alteradas ou sofrerem reduções significativas. Isso compromete os ciclos vitais da natureza ou promove desequilíbrio ecológico, afetando microrganismos não-alvo (BOLLAG, 1982; SMITH, 1988). ISMAIL e AHMAD (1994) postularam que no caso de pesticidas, a recuperação com relação à comunidade microbiana pode ser uma resposta ao desenvolvimento de resistência ao composto, ou a sua dissipação no ambiente reduzindo os efeitos sobre a comunidade.

Efeitos da aplicação do metalaxil sobre a atividade enzimática dos solos, expressos a partir da avaliação da atividade Dhase (Figuras 4, 5 e 6) não apresentaram resultados significativos. Foi detectada inibição inicial da atividade dessa enzima, revertida após sete dias de aplicação do fungicida nos três solos estudados. Embora tenha sido observado comportamento semelhante entre os valores de recuperação da enzima e o número de microrganismos não foi possível correlacionar significativamente as duas avaliações. Pesquisadores vêm tentando relacionar as atividades enzimáticas com a contagem em placa de microrganismos de solos (SANTOS, 1992). Porém, tem sido demonstrado que essa correlação somente é positiva com a adição de fonte de carbono como, por exemplo, a glicose.

FIGURA 4 - EFEITO DO METALAXIL NA ATIVIDADE ENZIMÁTICA Dhase NO SOLO DE ESTIVA GERBI - SP SUPLEMENTADO COM METALAXIL NAS DOSES DE 3 E $30 \mu \mathrm{g}$ i.a. $\mathrm{g}^{-1} \mathrm{E}$ CONTROLE $(P=\leq 0,05)$

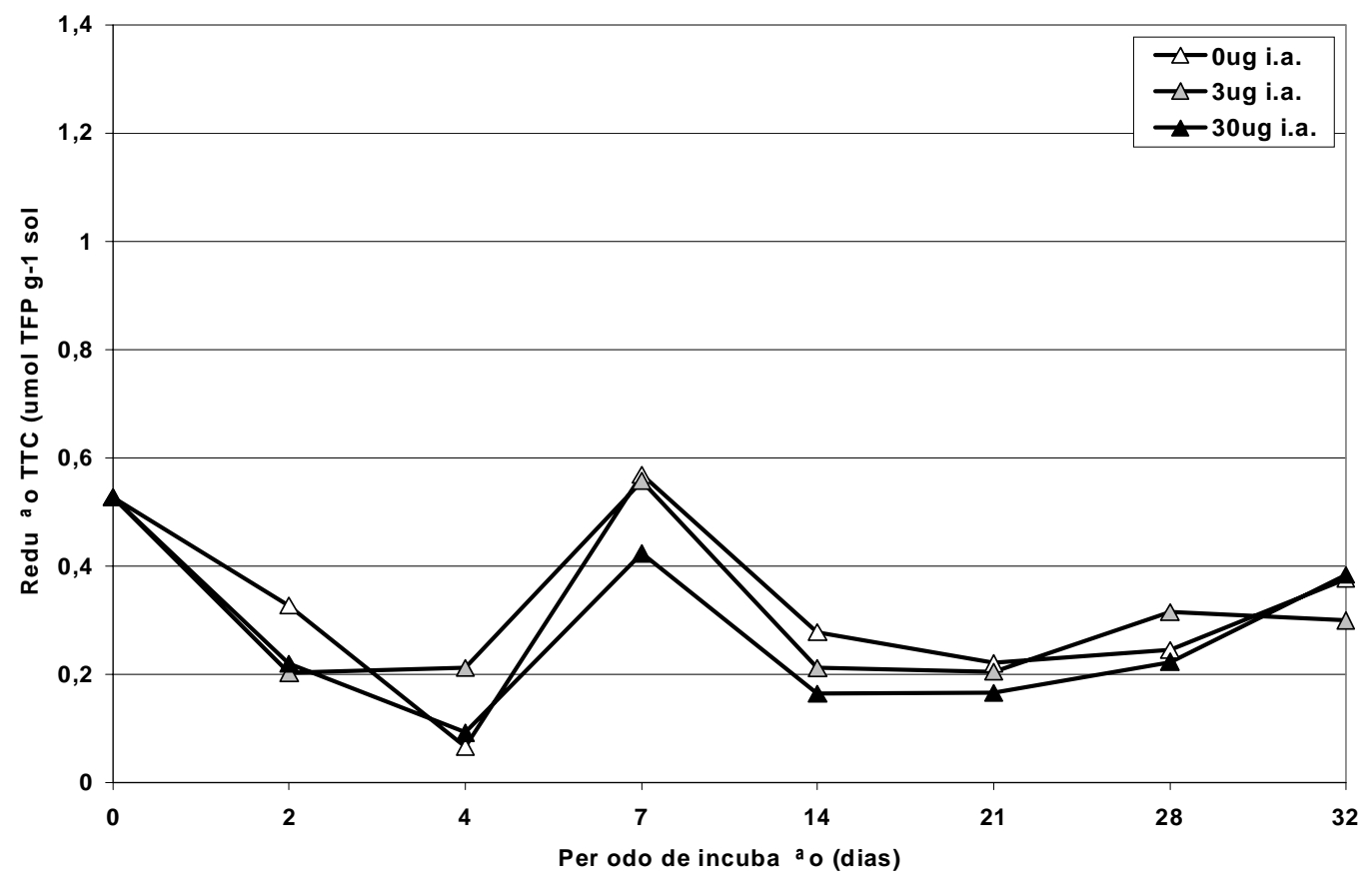


FIGURA 5 - EFEITO DO METALAXIL NA ATIVIDADE ENZIMÁTICA Dhase NO SOLO DE AGUAíSP SUPLEMENTADO COM METALAXIL NAS DOSES DE 3 E $30 \mu \mathrm{g}$ i.a. $\mathrm{g}^{-1} \mathrm{E}$ CONTROLE $(P=\leq 0,05)$

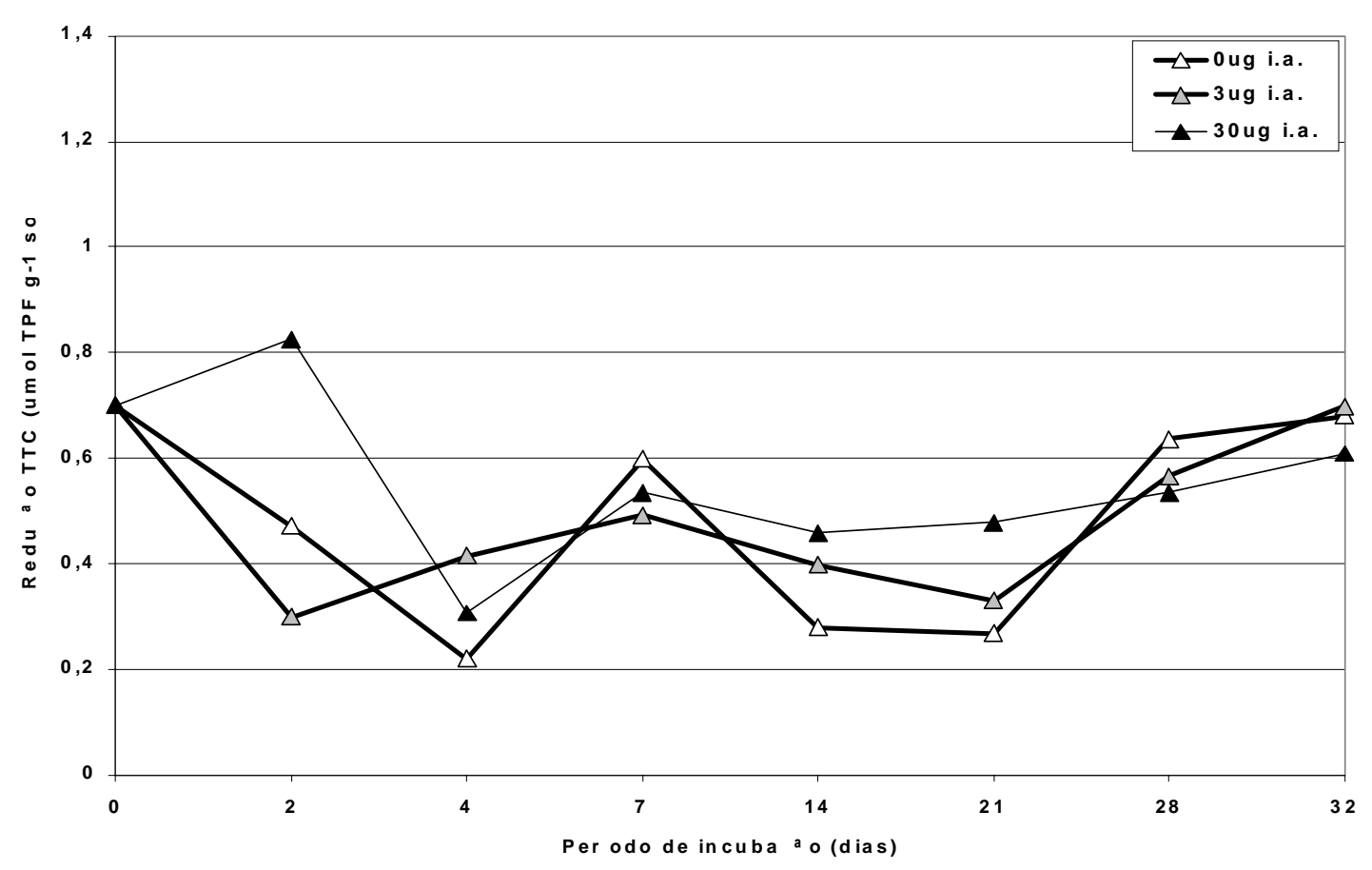

FIGURA 6 - EFEITO DO METALAXIL NA ATIVIDADE ENZIMÁTICA Dhase NO SOLO DE JAGUARIÚNA-SP SUPLEMENTADO COM METALAXIL NAS DOSES DE 3 E $30 \mu \mathrm{g}$ i.a. $\mathrm{g}^{-1}$ E CONTROLE $(P=\leq 0,05)$

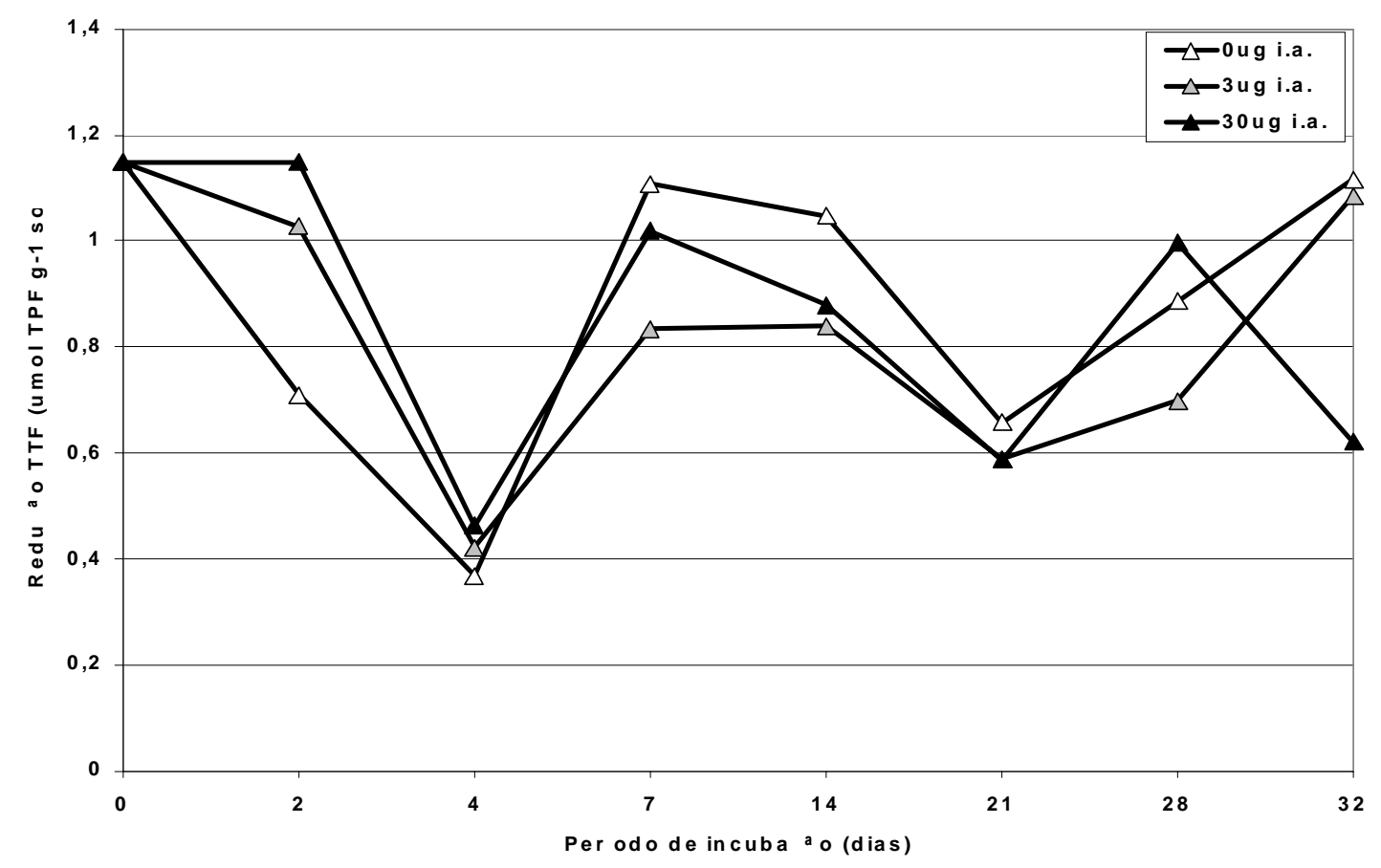


A influência dos pesticidas nas atividades enzimáticas já foi evidenciada por vários autores (GIANFREDA e BOLLAG, 1996; DICK, 1997; SCHÄFFER, 1997). Entretanto, somente SHETTY e MAGU (1998) trabalharam com os efeitos do metalaxil na atividade da Dhase. Observaram sua influência sobre a atividade dessa enzima, a qual pode ser acentuada por fatores como tempo e dose. Esses dados corroboram os obtidos neste estudo, sugerindo que a molécula age inibindo a Dhase, embora a inibição dependa também de outros fatores como dose aplicada, tipo de solo e microbiota presente.

A atividade da enzima Pase ácida foi inibida após aplicação de metalaxil nos três solos (Figuras 7, 8 e 9) em ambas as doses testadas do fungicida. Da mesma forma como a Dhase, a atividade da Pase ácida demonstrou capacidade de recuperação nos solos após 14 dias de incubação. Não foi possível, também neste caso, correlacionar os valores observados na contagem em placas com a atividade Pase ácida observada nos solos.

FIGURA 7 - EFEITO DO METALAXIL NA ATIVIDADE ENZIMÁTICA Pase ÁCIDA NO SOLO DE ESTIVA GERBI SUPLEMENTADO COM METALAXIL NAS DOSES DE 3 E $30 \mu$ g i.a. $g^{-1}$ E CONTROLE $(P=\leq 0,05)$

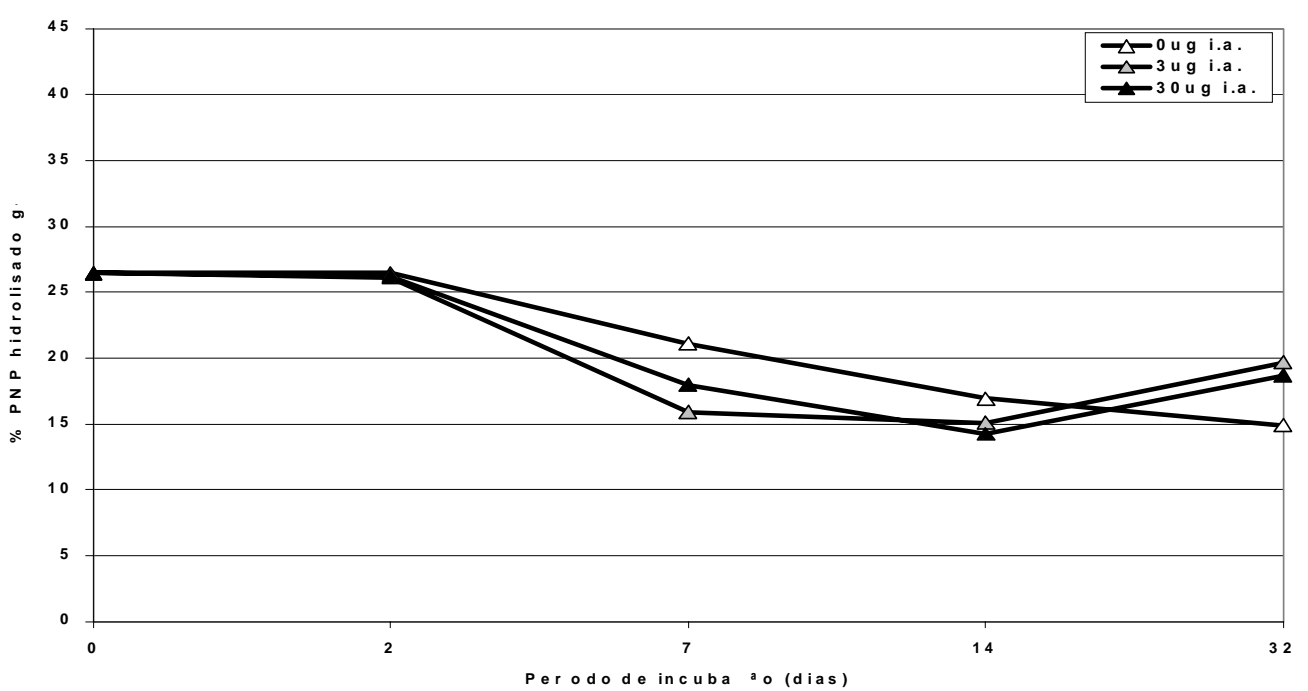

\section{FIGURA 8 - EFEITO DO METALAXIL NA ATIVIDADE ENZIMÁTICA Pase ÁCIDA NO SOLO DE AGUAÍ SUPLEMENTADO COM METALAXIL NAS DOSES DE 3 E $30 \mu \mathrm{g}$ i.a. $\mathrm{g}^{-1} \mathrm{E}$ CONTROLE $(P=\leq 0,05)$}

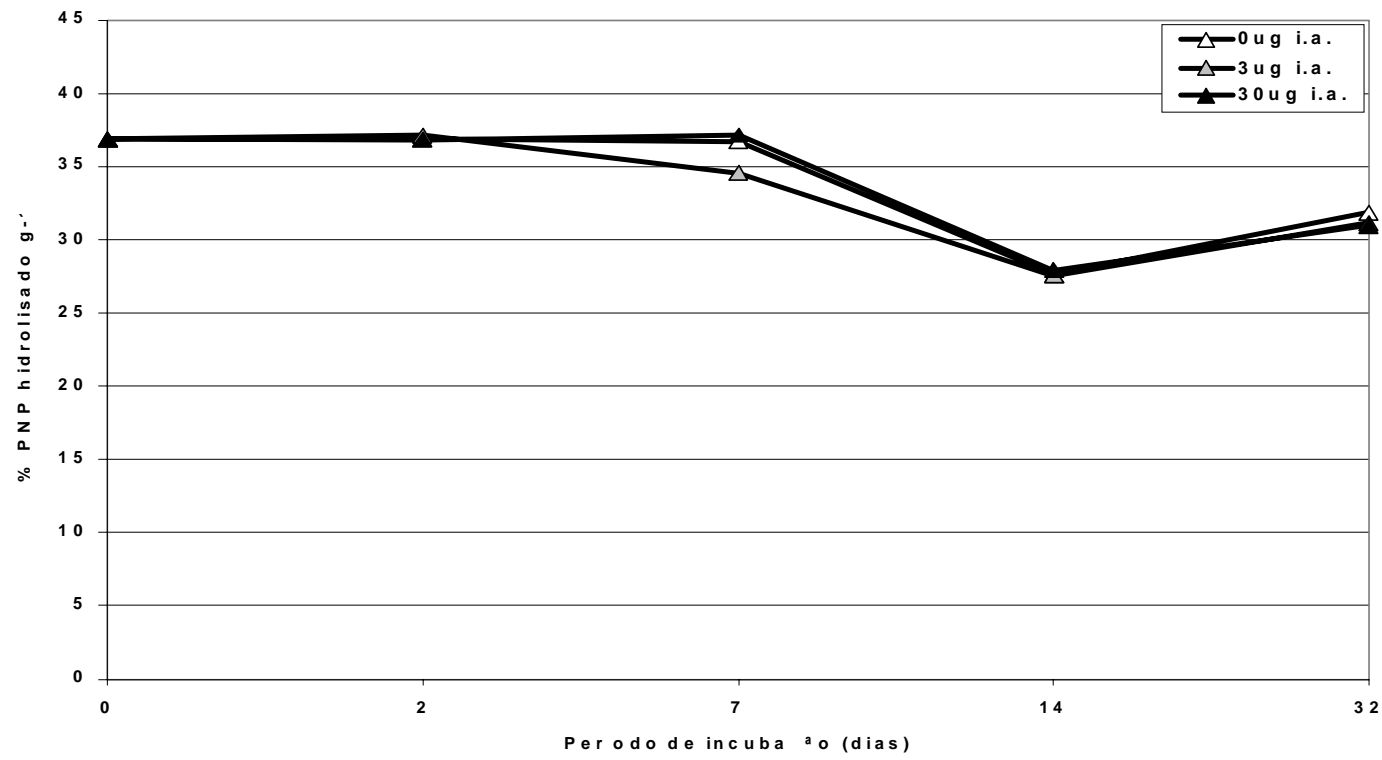




\title{
FIGURA 9 - EFEITO DO METALAXIL NA ATIVIDADE ENZIMÁTICA Pase ÁCIDA NO SOLO DE JAGUARIÚNA SUPLEMENTADO COM METALAXIL NAS DOSES DE 3 E $30 \mu$ g i.a. $g^{-1}$ E CONTROLE $(P=\leq 0,05)$
}

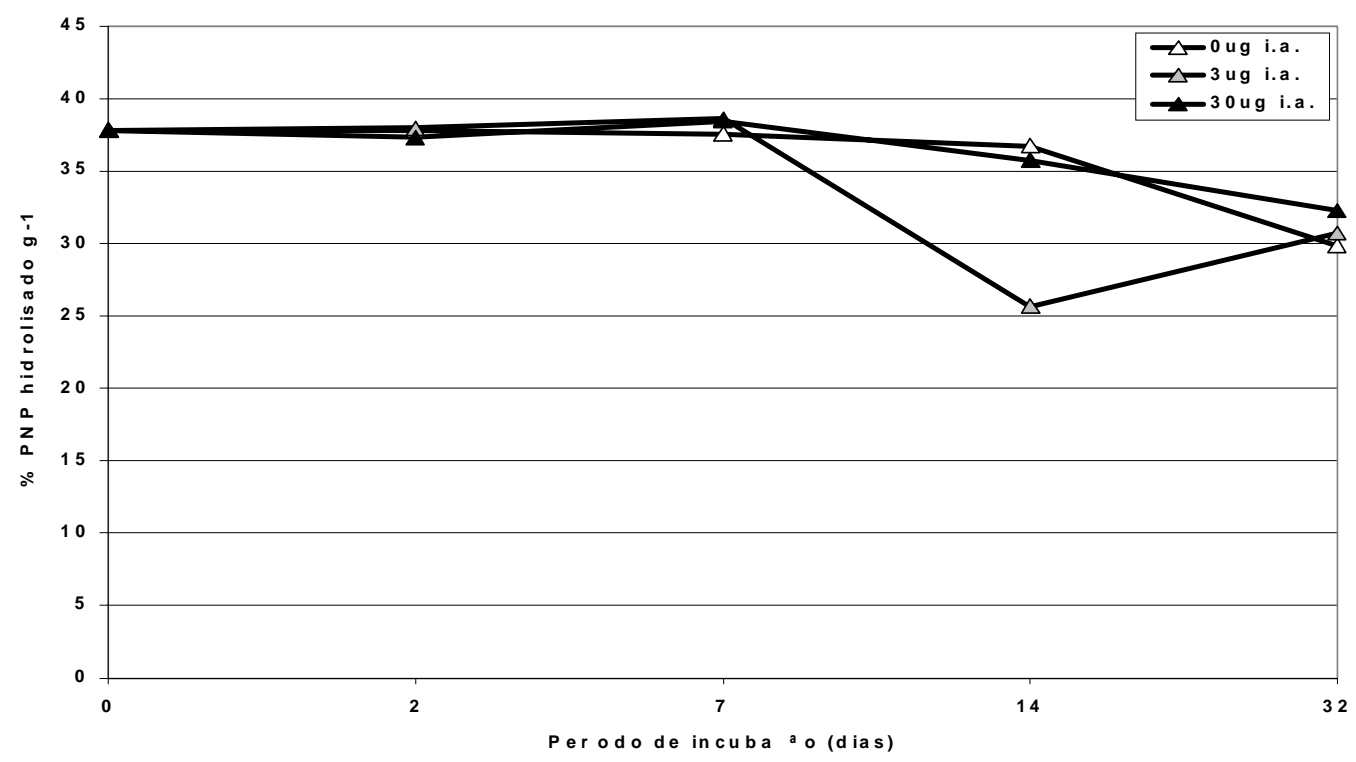

SANTOS (1992) afirmou que a Pase ácida é produzida por grande número de microrganismos do solo e que seu acúmulo resulta da atividade microbiana. Segundo SKUJINS (1976), a atividade dessa enzima não tem relação com o número de microrganismos ou com a atividade respiratória do solo embora, ocasionalmente, relate o teor de fósforo dos solos.

Entre as enzimas aqui avaliadas, a atividade da Dhase mostrou-se a mais sensível à presença do fungicida. Dessa forma, poderia ser aplicada como indicador da atividade microbiana em outros estudos sobre o efeito do metalaxil nas comunidades microbianas dos solos.

\section{CONCLUSÃO}

A utilização do fungicida metalaxil em doses superiores à recomendada pode alterar a microbiota do solo. As técnicas utilizadas neste experimento foram efetivas no sentido de avaliar o comportamento de fungos, bactérias e actinomicetos existentes em solos de diferentes regiões tropicais brasileiras com histórico de aplicação do fungicida metalaxil.

\begin{abstract}
METALAXIL ON SOIL MICROBIOT AND ENZYMATIC ACTIVITY

The effects of Metalaxyl on soil microorganisms collected in Sao Paulo districts of Aguai, Estiva, Gerbi and Jaguariuna (Brazil), supplemented with doses of 3 and $30 \mu \mathrm{g}$ a.i g $\mathrm{g}^{-1}$ for the period of 32 days were studied. Bacterial, actinomycets and fungi were monitored by plate counting and by acid phosphatase (Pase) and dehydrogenase enzymatic activity (Dhase). The Pase was evaluated by the method of p-nitrophenilphosphatase and the Dhase by the quantification of the produced red formazan. Predominance of bacterial population was observed in all soils, being the higher values of CFU g ${ }^{-1}$ observed in soils supplemented with the dose of $30 \mu \mathrm{g} \mathrm{a.i} \mathrm{g-1} \mathrm{of} \mathrm{Metalaxyl.} \mathrm{Fungal} \mathrm{population} \mathrm{presented} \mathrm{accentuated}$ decrease after compost incorporation. Dhase activity was inhibited by the presence of Metalaxyl in sandy and control soils. In clay soils the activity was incremented, being more significant in the period of 7 to 21 days, in both supplementation doses. Pase activity was inhibited in all three soils.
\end{abstract}

KEY-WORDS: METALAXYL; DEHYDROGENASE, ACID PHOSPHATASE; SOILS. 


\section{REFERÊNCIAS}

ALEF, K. Biological soil reclamation. Weinhem: VCH, 1995. 269 p.

ANDERSON, J.P.E. Pesticide effects on non-target soil microorganisms. In: HILL, I.R.; WRIGHT, S.J.E. Pesticide microbiology. New York: Academic Press, 1978. p.611-628.

ARX, J. A. von. Plant phatogenic fungi. Berlim: J. Cramer, 1987. 87 p.

BAILEY, A.M.; COFFEY, M.D. Biodegradation of metalaxyl in avocado soils. Phytopathology, v.75, p.135-137, 1985.

BAILEY, A.M.; COFFEY, M.D. Characterization of microorganisms involved in accelerated biodegradation of metalaxyl and metolachlor in soils. Canadian Journal of Microbiology, v.32, p.562-569, 1986.

BOLLAG, J.M. Microbial transformations of bioactive compounds. Boca Raton: CRC Press, 1982.

DICK, R.P. Soil enzymes activities as integrative indicators of soil health. In: PANKHHURST, B.M.; DOUBE, B.M.; GUPTA, V.V.S.R. (Ed.). Biological indicator of soil health. Wallingford: CAB International, 1997. p.121-156.

DROBY, S.; COFFEY, M.D. Biodegradation process and nature of metabolism of metalaxyl in soil. Annals of Applied Biology, v.118, p.543-53, 1991.

DROZDOWICZ, A. Os herbicidas e os microrganismos. Revista de Microbiologia, v.2, p.43-61,1971.

EMBRAPA. Centro Nacional de Pesquisa de Solos. Manual de métodos de análise de solo. Rio de Janeiro, 1997. $51 p$.

FAROOQI, M.; SOSNITZA, P.; SALEEMUDDIN, M.; ULBER, R.; SCHEPER, T. Stabilisation and analysis of glucose and hydrogen peroxide. Applied Microbiology and Biotechnology, v.52, p.373-79, 1999.

GIANFREDA, L.; BOLLAG, J.M. Influence of natural and anthropogenic factors on enzyme activity in soil. In: STOTZKY, G.; BOLLAG, J.M. (Ed.). Soil biochemistry. New York: Marcel Dekker, 1996. p. 123-193.

HILL, I.R. Pesticides microbiology: microbiological aspects of pesticides behaviour in the environmental. New York: Academic Press, 1978. p.79-136.

ISMAIL, B. S.; AHMAD, A.R. Attenuation of the herbicidal activities of glufosinate-ammonium and imazapyr in two soils. Agriculture, Ecosystems and Environment, v.47, p.279-285, 1994.

JOHNSTON, W.H.; CAMPER, N.D. Microbial degradative activity in pesticide pre-treated soil. Journal Environmental, Science and Health, v.26, p.1-14, 1991.

KÜSTER, E.; WILLIAMS, S. T. Selection of media for isolation of Streptomycetes. Nature, v.202, p.928-929, 1964.

MUSUMECI, M.R.; RUEGG, E.F. Degradation and residues of trifluralin and metalaxyl in soils treated with ${ }^{14} \mathrm{C}$-trifluralin and ${ }^{14} \mathrm{C}$-metalaxyl, under laboratory conditions. Pesquisa Agropecuária Brasileira, v.21, p.1023-1029, 1986.

OSTIZ, S. B.; MUSUMECI, M. R. Effect of agrotoxics in biological activity of two soils in laboratory experiments. Pesquisa Agropecuária Brasileira, v.24, p.19-25, 1989.

PAPINI, S.; ANDRÉA, M.M. Enhanced degradation of metalaxyl in gley humic and dark red latosol. Revista Brasileira de Ciência do Solo, v.24, p.469-474, 2000.

RACKE, K.D. Pesticide in the microbial ecosystem. In: RACKE, K.D.; COATS, J.R. Enhanced biodegradation of pesticides in the environment. Washington: ACS, 1990.

SANTOS, T. M. C. Avaliação do número e atividades enzimáticas de microrganismos na presença de aldicarbe e endosulfan no solo. Rio Claro, 1992. 142 p. Tese (Doutorado) - Instituto de Biociências do Campus de Rio Claro, Universidade Estadual Paulista Julio de Mesquita Filho.

SCHAFFER, A. Pesticide effects on enzyme activities in the soil ecosystem. In: BOLLAG, I. M.; STOTZKY, G. (Ed.). Soil Biochemistry. New York: Marcel Dekker, 1993. v.8, p.273-340.

SHETTY, P.K.; MAGU, S.P. In vitro effect of pesticides on carbon dioxide evolution and dehydrogenase activities in soil. Journal of Environmental Biology, v.226, p.22, 1998.

SKUJINS, J. Enzymes in soil. In: MACLAREN, A. D.; PETERSON, G. H. Soil biochemistry. New York: Marcel Dekker, 1976. p. $371-414$.

SMITH, A.E. Environmental chemistry of herbicides. Boca Raton: CRC Press, 1988.

SPESSOTO, A.M.; MELO, I.S.; FERRACINI, V.L. Dissipação do fungicida metalaxil em solos brasileiros. Revista Brasileira de Fitopatologia, v.25, p.596-601, 2000.

STATISTICA for Windows (programa de computador). Tulsa, Ok.: Statsoft, 2002.

TU, C.M.; BOLLEN, W.B. Effect of paraquat on microbial activities in soils. Weed Research, v.8, p.28-37, 1968.

VOSJAN, J.H. Respiratory electron transport system activities in marine environments. Hydrobiology Bulletim, v.16, p.61-68, 1982.

\section{AGRADECIMENTOS}

Agradecemos às instituições financiadoras CAPES e FAPESP pelo auxílio financeiro. 